\title{
A importância dos cicatrizadores personalizados na implantodontia atual: revisão de
}

\section{literatura}

\author{
The importance of personalized healers in current implantodontics: literature review \\ La importancia de los sanadores personalizados en la implantodoncia actual: revisión de la
} literatura

Recebido: 10/11/2021 | Revisado: 16/11/2021 | Aceito: 18/11/2021 | Publicado: 29/11/2021

\author{
Kleyson Barbosa Matias \\ ORCID: https://orcid.org/0000-0002-7394-4905 \\ Faculdade Independente do Nordeste, Brasil \\ E-mail: kleyson.matias33@gmail.com \\ Leonardo Soares Viana \\ ORCID: https://orcid.org/0000-0002-5491-8891 \\ Faculdade Independente do Nordeste, Brasil \\ E-mail: leosoaresbdo95@yahoo.com.br \\ Larissa Ledo Pereira Sant'Ana \\ ORCID: https://orcid.org/0000-0002-9829-9375 \\ Faculdade Independente do Nordeste, Brasil \\ E-mail: larissaledo@hotmail.com
}

\begin{abstract}
Resumo
Introdução: A exodontia de um elemento dentário resulta em mudanças na arquitetura óssea e remodelação dos tecidos moles subjacentes. A implantação imediata surgiu com o propósito de, principalmente, preservar as paredes do alvéolo; mas, pode estar associado à recessão marginal. Os cicatrizadores personalizados vieram para suprir essa demanda; visto que, sela os implantes e leva a uma cicatrização individualizada. O contorno gengival do implante é uma área de suma importância no que diz respeito aos resultados estéticos e posterior adaptação das coroas dentárias. Objetivo: Através de uma revisão de literatura, demonstrar as vantagens, desvantagens e auxílio dos cicatrizadores personalizados no processo de cicatrização do rebordo gengival após cirurgia de implantes. Metodologia: Será realizada uma pesquisa bibliográfica na língua portuguesa e inglesa no Scielo, PubMed, Lilacs e Bireme usando os seguintes termos: cicatrizador personalizado; implantodontia; implante imediato. Artigos completos serão selecionados e incluídos nesta revisão. Resultados esperados: Colaborar com uma discussão científica já existente e na compreensão da técnica com cicatrizadores personalizados e seu auxílio na Implantodontia. Conclusão: A utilização dos cicatrizadores personalizados otimizam o processo de recuperação pós operatória, auxiliando na obtenção de um resultado positivo no tratamento reabilitador.
\end{abstract}

Palavras-chave: Cicatrização; Gengiva; Condicionamento tecidual.

\begin{abstract}
Introduction: The extraction of a dental element results in changes in bone architecture and remodeling of the underlying soft tissue. The immediate implantation came with the purpose, mainly, to preserve the alveolus walls; but, it may be associated with marginal recession. Personalized healers came to meet this demand; as it seals the implants and leads to individualized healing. The gingival contour of the implant is an area of paramount importance with regard to aesthetic results and subsequent adaptation of dental crowns. Objective: Through a literature review, demonstrate the advantages, disadvantages and assistance of personalized healers in the gingival ridge healing process after implant surgery. Methodology: A bibliographic search will be carried out in Portuguese and English in Scielo, PubMed, Lilacs and Bireme using the following terms: personalized healing; implant dentistry; immediate implant. Full articles will be selected and included in this review. Expected results: Collaborate with an existing scientific discussion and understanding of the technique with personalized healing and its assistance in Implantology. Conclusion: The use of personalized healers optimizes the postoperative recovery process, helping to obtain a positive result in the rehabilitation treatment.
\end{abstract}

Keywords: Healing; Gum; Tissue conditioning.

\section{Resumen}

Introducción: La extracción de un elemento dental produce cambios en la arquitectura ósea y remodelación del tejido blando subyacente. La implantación inmediata vino con el propósito, principalmente, de preservar las paredes alveolares; pero puede asociarse con la recesión marginal. Los curanderos personalizados vinieron a satisfacer esta demanda; ya que sella los implantes y conduce a una curación individualizada. El contorno gingival del implante es un área de suma importancia para los resultados estéticos y la posterior adaptación de las coronas dentales. Objetivo: A 
través de una revisión de la literatura, demostrar las ventajas, desventajas y asistencia de los curanderos personalizados en el proceso de cicatrización del reborde gingival después de la cirugía de implantes. Metodología: Se realizará una búsqueda bibliográfica en portugués e inglés en Scielo, PubMed, Lilacs y Bireme utilizando los siguientes términos: curación personalizada; implantología; implante inmediato. Los artículos completos serán seleccionados e incluidos en esta revisión. Resultados esperados: Colaborar con una discusión científica existente y comprensión de la técnica con curación personalizada y su asistencia en Implantología. Conclusión: El uso de curanderos personalizados optimiza el proceso de recuperación postoperatoria, ayudando a obtener un resultado positivo en el tratamiento rehabilitador.

Palabras clave: Curación; Encía; Acondicionamiento de tejidos.

\section{Introdução}

O desafio da realização de cargas imediatas abrange fatores que vão além da estabilidade primária. É preciso manter a arquitetura óssea e gengival que envolvem o implante, buscando atingir os ideais estéticos e funcionais para atingir o sucesso. (Santos, 2018).

A técnica de implante imediato possui um alto grau de complexidade em relação aos pontos estético e biomecânico. O sucesso do tratamento depende de um planejamento multidisciplinar e terapêutico, ambos ajustados para se obter restaurações que cumpram o dever estético. Um bom manejo dos tecidos moles circundantes é o ponto chave para atingir os objetivos do tratamento. (Carvalho, 2020).

Para se obter um resultado natural, são necessários ajustes na coroa provisória sobre implante, para que haja condicionamento dos tecidos moles, mantendo um contorno gengival com aspecto natural e harmônico. O perfil de emergência satisfatório se inicia na escolha do provisório de formato côncavo, permitindo o alojamento da margem gengival ao provisório, que deverá apresentar características anatômicas que auxiliem na alocação gengival. (Santos, 2018).

Os cicatrizadores precisam seguir o tamanho dos dentes que serão substituídos para melhor guiarem a cicatrização da estrutura circundante. Os modelos disponíveis no mercado, do tipo pré-fabricados, nem sempre conseguem suprir todas as necessidades do caso, podendo retardar todo o processo de maturação dos tecidos. Os modelos personalizados vêm para preencher essa necessidade no suporte aos tecidos, otimizando o tempo e o resultado estético quando se trata da preservação papilar e da estabilidade presente na margem gengival. (Santos, 2020).

A fabricação do cicatrizador personalizado no implante imediato, não pode causar injurias ao tecido circundante e realizar a sua função básica de manter a arquitetura da gengiva até estar apto para a implantação da coroa definitiva. O processo de personalização deve ser realizado com o máximo de lisura afim de evitar qualquer chance de retenção de alimentos e por vez a formação de biofilme, o que poderia afetar negativamente o processo de cicatrização do periodonto. (Santana, 2018).

O uso do cicatrizador personalizado permite uma redução de custos no tratamento proposto além de dos resultados promissores. Para o melhor aproveitamento desses benefícios, é preciso realizar uma indicação correta, possuir destreza na técnica cirúrgica e utilizar protocolos protéticos. (Miquelleto, 2019).

O objetivo do presente estudo foi demonstrar, por meio de uma revisão de literatura, as vantagens do uso de cicatrizadores personalizados no processo de cicatrização do rebordo gengival dos implantes.

\section{Metodologia}

Este trabalho foi realizado com base nos preceitos do tipo de revisão narrativa, comumente conhecida como revisão exploratória ou revisão tradicional (Ferenhof, 2016). Foi realizada uma pesquisa bibliográfica na língua portuguesa, espanhola e inglesa nas bases de dados Scielo, PubMed, Lilacs e Bireme, usando os seguintes termos: cicatrizador personalizado; implantodontia, implante imediato. Foram selecionados artigos cuja publicação tenha menos que 25 anos, artigos que descrevem o uso dos cicatrizadores personalizados e artigos sobre implantes imediatos para auxiliar na base da escrita deste trabalho, por meio de uma primeira leitura do título, logo após realizou-se a leitura do resumo para inclusão e posteriormente a íntegra. Artigos 
completos foram selecionados e incluídos nesta revisão. Os trabalhos que abordaram a utilização de cicatrizadores pré-fabricados e técnicas de implante que não sejam o implante imediato, bem como trabalhos publicados a mais de 25 anos foram removidos da base de dados. Em primeira busca foram pré-selecionados 47 artigos, após leitura de resumo e aplicação dos critérios de exclusão, foram descartados 25 artigos que não se adequavam aos critérios propostos e utilizamos os 22 que estavam dentro do pretendido para a elaboração deste trabalho.

\section{Revisão de Literatura}

Para que um indivíduo tenha um bem estar geral, a dentição participa ativamente de funções como estética, fonação e mastigação. A perda de um ou mais órgãos dentais é capaz de provocar transtornos no paciente de forma generalizada, o que prejudica, inclusive, relações sociais.

A substituição dentária tem sido estudada continuamente e, com o passar do tempo e com os avanços da Odontologia Moderna, os implantes osseointegráveis surgiram promovendo reabilitação, estabilidade oclusal, harmonia e saúde aos pacientes que, por motivos alheios, perderam dentes naturais (Amorim, et al., 2019).

\subsection{Implantodontia}

As reabilitações orais com implantes para substituição de dentes perdidos precocemente já são bem estudadas e documentadas. A não-manutenção dos dentes na cavidade oral pode ter acontecido por fracassos endodônticos, periodontais, cáries, traumatismos, iatrogenias, protéticos, etc. Dessa forma, tornou-se um procedimento altamente previsível e bem embasado cientificamente (Florentino Filho, et al., 2012).

Branemark e colaboradores estudaram os princípios da osseointegração na Odontologia, o que possibilitou novos horizontes para a área da reabilitação. Segundo eles, é definido como "uma conexão estrutural e funcional entre a base óssea e a superfície de um implante sob carga funcional" (Bocardi, et al., 2000).

Carvalho e colaboradores, em 2006, relataram em seu estudo que, nas últimas décadas, a dificuldade de reabilitar o paciente edêntulo, parcial ou totalmente, foi suprida com a utilização de implantes osseointegráveis, em grande parte dos casos. Com o uso dessa técnica, é possível que o paciente recupere a estética e a funcionalidade de seu sistema estomatognático.

Segundo Mavrogenis et al. (2009), o material que compõe o implante dental é extremamente biocompatível, o que minimiza danos nocivos ao organismo e estimula o processo de reparação, cura, da maneira mais eficaz possível. A cicatrização ao redor do implante ocorre biologicamente até sua superfície ser recoberta com osso recém-formado.

Através da união física do implante com o osso receptor, ocorre o fenômeno da osseointegração, garantindo sucesso clínico. Esses níveis de sucesso com a união estrutural e funcional entre osso e implante, nos dias atuais, ultrapassam os $90 \%$. Porém, para que seja obtido tal índice, é preciso que o CD realize uma anamnese criteriosa da saúde geral do paciente, seguir criteriosamente regras de biossegurança, amplo conhecimento da área e conhecer as variáveis de um implante, por exemplo (Martins, et al., 2011).

Se a osseointegração não ocorrer ou se perder por algum motivo, forma-se um tecido conjuntivo fibroso ao redor do implante - o que é caracterizado como insucesso, já que o maior objetivo do implante dental é obter fixação biológica para uma ancoragem estável e permanente, suportando a carga mastigatória (Florentinho Filho, et al., 2012).

Uma falha no planejamento promoverá insucessos clínicos à curto, médio ou longo prazo. Dessa forma, os implantes possuem indicações e contraindicações. Dentre as indicações, podemos citar:

1. Edêntulos parciais/totais;

2. Substituição de elementos unitários;

3. Quando o número de pilares naturais não é suficiente para próteses fixas; 
4. Rejeição/insatisfação com próteses totais (PT) ou parciais removíveis (PPR) (Francischone, et al., 2006).

\subsection{Tempos Cirúrgicos}

Os protocolos antigos de Branemark previam que se aguardasse cerca de 6 a 12 meses depois de uma exodontia, para só depois inserir um implante no mesmo local. Dessa forma, haveria a cicatrização do tecido ósseo e gengival da região (Zorzo, 2003).

Em meados dos anos 80, as tentativas de implantação imediata foram iniciadas, ou seja, apenas um tempo cirúrgico: insere-se o implante logo após a extração dentária. Mathys (1998) cita como vantagens a preservação da camada óssea, a dimensão dos tecidos moles, redução de tempo e favorece a estética (Zorzo, 2003).

Kan et al. (2010) e Januário et al. (2011) em seus estudos, relatam que os sítios dos dentes anteriores possuem parede óssea fina, o que pode levar a uma reabsorção acentuada pós extração. A avaliação minuciosa de exames clínicos e imaginológicos junto à uma determinação do arquétipo gengival torna-se muito importante nos planejamentos cirúrgicos, influenciando na tomada de decisões (Aquino, et al., 2015).

Os implantes também se classificam de acordo com o tempo de sua instalação. Os tardios são aqueles realizados após a completa cicatrização óssea; os precoces, cerca de 1 mês após a extração, quando já houver cicatrização gengival; e os de carga imediata, onde a colocação do novo elemento dentário pode ser feita em até 72 horas após a colocação do parafuso de titânio (Assada, et al., 2019; Miqueleto, et al., 2019).

$\mathrm{Na}$ implantação imediata, deve-se buscar uma região com maior volume ósseo para estabilização do implante, havendo a formação de um gap entre a tabua óssea vestibular e a superfície do implante (SANTOS, 2018). A realização de uma exodontia atraumática associado a enxerto ósseo e gengival combinado logo após a extração mostrou resultados promissores, melhorando estética e conforto aos pacientes (Aquino et al., 2015; Miqueleto, et al., 2019).

\subsection{Cicatrizadores Personalizados}

$\mathrm{Na}$ Implantodontia, as questões técnicas passaram por um grande avanço, fazendo com que as pesquisas atuais se concentrem em viabilizar melhores resultados estéticos. Os protocolos buscam cada vez mais a manutenção dos tecidos periimplantares e periodontais, para que se crie uma aparência natural do contorno gengival e da luminosidade da coroa protética (Zorzo, 2003; Miquelleto, et al., 2019)

As cargas imediatas só podem ser consideradas sucesso quando, além de preservação estética, obtém-se estabilidade primária e boa arquitetura óssea e gengival. Essa forma de implantação permite ao paciente boa recuperação estética e menor tempo de cicatrização (Frasca, 2015; Santos, 2018).

Após a instalação do implante imediato, existem algumas opções para reabilitação provisória do paciente: uso do cicatrizador; fechamento do implante para posterior reabertura; ou instalação de uma coroa provisória (Assada, 2019). Ainda, após a implantação, é necessária uma ancoragem mais palatinizada numa região de maior volume ósseo, melhorando a estabilidade. Assim, forma-se um gap entre a superfície do implante e a tábua óssea vestibular. Esse espaço deve ser preenchido por material biocompatível ou enxerto ósseo autógeno, compensando a remodelação óssea, favorecendo a fixação do implante e garantindo melhor regeneração dos tecidos duros e moles (Santos, 2018; Zorzo, 2003). Apesar disso o implante necessita estar bem posicionado tridimensionalmente, este entendimento é visto como algo fundamental para se obter o êxito no mesmo, sendo necessário a prévia avaliação das estruturas e espaço onde será realizado o implante (Vieira, 2006).

O preenchimento do gap e a enxertia gengival mantém o rebordo alveolar, preservam o contorno gengival e minimizam a remodelação fisiológica do alvéolo. Os implantes recebem parafusos ou cicatrizadores padronizados e, mantidos submersos ou expostos, não livram que ocorra descaracterização do contorno cervical das coroas dentárias naturais. Já o uso de cicatrizadores 
personalizados tende a obter uma cicatrização individualizada, o que auxilia a confecção de futuras coroas e garante mais conforto ao paciente (Frasca, 2015; Assada, 2019).

Os cicatrizadores devem ter a largura próxima ao do dente que está substituindo. Existem algumas formas de produção desses cicatrizadores:

- Resina flow: O preparo do cicatrizador começa a ser feito no modelo de estudo, obtido por meio de uma moldagem feita com uma boa silicona de condensação. No modelo, é feita a marcação do limite do contorno gengival ao redor do dente para orientar o nível do desgaste. A concavidade equivalente ao alvéolo é preenchida com resina tipo flow até o nível cervical. Um microbrush é fixado no centro da resina para facilitar sua posterior remoção do modelo. Depois da polimerização da resina, uma perfuração é feita na área central para facilitar a posterior união como cilindro provisório. Essa perfuração é definida pelo planejamento do posicionamento 3D do implante e deve ser compatível com o guia cirúrgico. Logo após, se dá início ao acabamento, o polimento e a desinfecção da peça, deixando-a pronta para o uso cirúrgico. Um cilindro provisório é aparafusado sobre o implante para captura do cicatrizador. O corpo pré-fabricado em resina é posicionado sobre o alvéolo para confirmação de sua adequação. Em seguida, utilizam-se pequenas porções de resina para capturá-lo; a resina é imediatamente fotopolimerizada para reduzir o risco do escoamento deste material para dentro do alvéolo. Uma vez capturado o cilindro, o conjunto é removido e o espaço remanescente é preenchido, respeitando-se o contorno vertical e horizontal da área e o perfil emergente é confeccionado fora da boca. Finalmente, o cicatrizador polido (inclusive em sua porção interna) e desinfetado é aparafusado sobre o implante. Aos 7 dias de pós-operatório, a sutura é removida e o cicatrizador momentaneamente removido para observar a reparação do tecido mole. Depois de 45 dias, a cicatrização já avançada exibe melhor definição do perfil do tecido mole peri-implantar. A arquitetura tecidual original é perpetuada com a manutenção constante do perfil de emergência coincidente no cicatrizador, no transferente personalizado e no pilar definitivo em zircônia (Miquelleto, et al., 2019; Vasconcelos, et al., 2017).

- Multifuncional de PEEK: O preparo é realizado de acordo com a altura interoclusal do paciente e com o uso de um dente de estoque pré-fabricado. Realiza-se os ajustes necessários no dente de estoque com fresas, para que se adapte na região dentária. Para unir o implante e a unidade provisória, utiliza-se resina acrílica autopolimerizável. Com isso, todos os espaços do alvéolo são preenchidos. O provisório deve permanecer em infra-oclusão até que haja a osseointegração do implante e a confecção da coroa definitiva (Santos, 2018).

\section{Considerações Finais}

O tema abordado ainda não possui uma base de dados considerável, é preciso que mais autores o utilizem em suas pesquisas para uma melhor compreensão sobre o mesmo. A utilização dos cicatrizadores personalizados contribuem durante a recuperação pós operatória dos tecidos peri implantares, preservando a arquitetura óssea do rebordo alveolar e otimizando os resultados no tratamento. Outros momentos também são relevantes na obtenção do sucesso desejado, como uma correta execução no protocolo de inserção do implante no alvéolo, respeitando a técnica utilizada, e também a contribuição do paciente nos cuidados e higienização para uma perfeita cicatrização da região operada. A abordagem do tratamento reabilitador por implante tende a ser multidisciplinar, e multifatorial para o sucesso no tratamento proposto.

\section{Referências}

Amorim, A. V., Comunan, C. R., Ferreira Neto, M. D., \& Cruz, E. F. (2019). Implantodontia: Histórico, Evolução e Atualidades. Id on Line. Rev. Mult. Psic. 13(45), 36-48. http://idonline.emnuvens.com.br/id

Aquino, G. O., Duarte, L. C. R., Gorga, S. N. A., Joly, J. C., \& Peruzzo, D. C. (2015). Implante imediato com temporização imediata em área estética: relato de caso clínico. Ciência e Odontologia: casos clínicos baseados em evidências científicas. 1(1):200-205. 
Assada, F., Silva, R. S., \& Poluha, R. L. (2019). Cicatrizadores personalizados: relato de caso. Rev Estomatol Herediana. 29(4):291-96.

Bocardi, K., Rodrigues, A., Miranda, J. Á., Pagio-ro, P. F., \& Esteves, S. R. R. (2000). Implantes osseointegrados. Rev Ciên Odontol; 3(3):73-82.

Carvalho, M. F. D. (2020). Implante imediato com provisionalização imediata unitária. Instituto Universitário de Ciências da Saúde. Gandra, 39.

Carvalho, N. B., Gonçalves, S. L. M. B., Guerra, C. M. F., \& Carreiro, A. F. P. (2006). Planejamento Em Implantodontia: Uma Visão Contemporânea. Rev. Cir. Traumatol. Buco-Maxilo-Fac., 6(4), 17 - 22.

Ferenhof, H. A., \& Fernandes, R. F. (2016). Desmistificando a revisão de literatura como base para redação científica: método SSF. Revista ACB, 21(3), 550563.

Florentino Filho, A. T. C., Ataíde, W. S., \& Pereira, A. F. V. (2012). O Implante Dentário Como Uma Alternativa Para Pacientes Periondontais: Uma Revisão De Literatura. Rev. Ciênc. Saúde, São Luís, 14(1), 53-59.

Francischone, C. E., Filho, H. N., \& Matos, D. A. D. (2006). Osseointegração e tratamento multidisciplinar. São Paulo: Quintessence Editora Ltda. Cap. 4, p.5566.

Frasca, S. H. M., Barbosa, S. L., Valadares, K., Joly, J. C., \& Martinez, E. F. (2015). Implante imediato associado à reconstrução tecidual e temporização. Ciência e Odontologia: casos clínicos baseados em evidências científicas. Organizadores, José Luiz Cintra Junqueira, Marcelo Henrique Napimoga. -Campinas: Mundi Brasil. 1(1):188-193.

Januário, A. L., Duarte, W. R., Barriviera, M., Mesti, J. C., Araújo, M. G., \& Lindhe, J. (2011). Dimension of the facial bone wall in the anterior maxilla: a conebeam computed tomography study. Clin Oral Implants Res. Oct;22(10):1168-1171.

Kan, J. Y., Morimoto, T., Rungcharassaeng, K., Roe, P., \& Smith, D. H. (2010). Gingival biotype assessment in the esthetic zone: visual versus direct measurement. Int J Periodontics Restorative Dent; 30(3):237-43.

Martins, V., Bonilha, T., Falcón-Antenucci, R. M., Verri, A. C. G., \& Verri, F. R. (2011). Osseointegração: Análise De Fatores Clínicos De Sucesso E Insucesso. Rev. Odont. de Araçatuba, 32(1), 26-31.

Mavrogenis, A. F., Dimitriou, R., Parvizi, J., \& Babis, G. C. (2009). Biology of implant osseointegration. J Musculoskelet Neuronal Interact. 9(2):61-71.

Mathys, E. C. (1998). Immediate implants: indications and clinical decision making. J Col Dent Assoc, 77(4), 20-5.

Miquelleto, D. E. C., Morita, R., \& Son, A. (2019). Cicatrizador Personalizado em Resina Composta: Uma Técnica de Provisionalização. The International Journal of Oral \& Maxillofacial Implants, 4:602-606.

Santana, D. S. P., Dultra, F. K. A. A., Dultra, J. A., Oliveira, F., \& Corrêa, M. P. (2018). Cicatrizador personalizado em implantes imediatos. Revista Odontológica de Araçatuba, Araçatuba, 39:9-12.

Santos, C. D. D. (2020). Utilização Da Tecnologia CAD /CAM Na Obtenção De Cicatrizadores Personalizados - Revisão Narrativa. Universidade Fernando Pessoa. pp 27.

Santos, F. V. D. (2018). Implante imediato com provisionalização imediata através de cicatrizador multifuncional de peek. Universidade Do Sul De Santa Catarina. Palhoça, pp 36.

Vasconcelos, L. W., Hiramatsu, D. A., Paleckis, L. G. P., Francischone, C. E., \& Vasconcelos, R. C. B. (2017). Cicatrizadores personalizados sobre implantes imediatos em áreas de molares: preservando a arquitetura original dos tecidos. The International Journal Of Oral And Maxillofacial Implants. 2(2).

Vieira, L. F. N., Vidigal Júnior, G. M., Cardoso, E., Harari, N. D., \& Dias, E. C. (2006). Posição tridimensional ideal do implante. Rev. bras. implantodontia, $19-22$.

Zorzo, G. (2003). Pilares Personalizados: Uma Comparação Entre Os Sistemas Em Uso Clínico. 44f. Monografia - (Especialização) - Universidade Federal de Santa Catarina. 